\title{
Planta de Alimentos Nutritivos: aportes de la extensión universitaria para mejorar la calidad nutricional de los sectores vulnerables
}

\author{
Amanda Rocío Merino \\ Área de Comunicación. \\ Secretaría de Extensión Universitaria. \\ Universidad Nacional del Litoral.
}

El problema del hambre y la desnutrición es un tema presente, en mayor o menor medida, en la agenda pública mundial.

Si bien la responsabilidad de mitigar esta situación es de los gobiernos a partir de la definición de políticas públicas, instituciones privadas y organizaciones sociales se han apropiado de esta problemática con el fin de contribuir a minimizar la gravedad de las consecuencias sociales.

En este sentido, Universidad Nacional del Litoral (UNL) se propuso incorporar a su política de extensión estrategias de intervención social que permitan mejorar la calidad nutricional de los sectores vulnerables.

Es así que la UNL creó hace siete años el Programa de Alimentos de Interés Social en el ámbito de la Secretaría de Extensión Universitaria, el cual fue impulsado a partir de los conocimientos científicos y tecnológicos desarrollados por los docentes de la Universidad.

Actualmente, el Programa se sustenta en tres ejes centrales: desarrollo de conocimientos, elaboración de alimentos y educación alimentaria.

\section{La Planta de Alimentos Nutritivos}

Enmarcada en el eje Elaboración de alimentos, la Planta de Alimentos Nutritivos fue creada en el año 2007 y tiene como socio al Banco Credicoop
Cooperativo Limitado.

La Planta produce alimentos de alto valor nutricional, bajo los requerimientos estipulados por la FAO (Organización de las Naciones Unidas para la Agricultura y la Alimentación). Los alimentos se elaboran a partir de vegetales deshidratados y enriquecidos con proteínas, hierro y vitamina $C$. Se presentan en forma de guisos y están envasados al vacío, con papel metalizado de polipropileno bilaminado, lo cual permite preservar la calidad y el sabor.

Hoy en día la Planta elabora cinco productos: guisos de lenteja, de arroz y de fideos, además de arroz primavera y cuatro quesos. Son de fácil preparación, no necesitan cadena de frío, tienen una larga vida útil y tienen muy bajo costo.

Los alimentos tienen como principales destinatarios a organizaciones sociales, comedores comunitarios, escuelas, centros de adultos mayores, centros barriales y asociaciones vecinales que tengan planes alimentarios incorporados.

Actualmente la Planta está desarrollando -en coordinación con el Instituto de Tecnología de Alimentos de la Facultad de Ingeniería Química - un proyecto tecnológico para el secado de verduras y hortalizas. Se trata de una planta de secado cuya producción será utilizada tanto para la propia Planta de Alimentos como para la comercialización en el mercado regional. La ubicación de esta planta de secado está prevista en el ámbito de la escuela secundaria de Agricultura, Ganadería y Granja que depende de la UNL. Este proyecto se sumaría a la planta de elaboración de quesos ovinos existente, con lo que se estaría consolidando un espacio de transformación de la producción primaria.

A su vez, esta iniciativa constituye un agregado de valor que bien podrá articularse con acciones de producción comunitarias en marcha, como es el caso del Programa ProHuerta que lleva adelante el Instituto Nacional de Tecnología Agropecuaria (INTA)

\section{Estrategias de financiamiento}

Además del aporte sustancial que realiza el Banco Credicoop, la Planta recibe la contribución de los asociados solidarios. La figura del asociado permite, a partir de una donación mensual y voluntaria, destinar raciones de alimentos nutritivos a aquellos comedores y organizaciones sociales que los necesitan. En la actualidad el número de asociados, entre personas físicas y empresas, llega casi a 300. A partir de este aporte se reparten mensualmente ocho toneladas de alimentos.

A su vez, anualmente la campaña Reciclar/ Donar/Alimentar organizada desde el Programa de Extensión Ambiente y Sociedad aporta raciones a los comedores escolares. Bajo el lema "Un papel que 
se recicla es un papel que alimenta" se recolectan papeles y cartones en toda la comunidad universitaria durante el mes de diciembre. Los papeles acopiados son entregados a la empresa Celulosa Moldeada SA que los utiliza como materia prima para su producción. La empresa retribuye el valor en raciones para la Planta de Alimentos.

\section{Comedores universitarios}

Desde 2008, los alimentos nutritivos elaborados comenzaron a incorporarse en el menú del comedor universitario de la Universidad. Desde 2011, estos productos se incluyeron en las dietas de los comedores de las Universidades Nacionales de Mar del Plata, La Pampa y del Nordeste. Este año se sumó la Universidad Nacional de Río Cuarto.

\section{Reconocimiento al compromiso social}

Además de las acciones periódicas mencionadas más arriba, la Planta tuvo una importante presencia en situaciones de emergencia a nivel nacional e internacional. En el año 2007, se distribuyeron 100000 raciones a los inundados de la ciudad de Santa Fe.

En el año 2010, se enviaron a los damnificados por el terremoto de Haití, cuatro toneladas de alimentos que fueron distribuidos a través de la Comisión Cascos
Blancos. En ese mismo año se llevaron 11000 raciones para las víctimas del tornado que azotó al pueblo formoseño de Pozo del Tigre.

En abril de 2013, se realizó una donación de 5000 raciones de alimentos a los damnificados por el fuerte temporal que azotó a varias ciudades de la provincia de Buenos Aires y a la Capital Federal, principalmente a la ciudad de La Plata, que fue la más afectada.

La Planta ha recibido en estos años reconocimientos y distinciones por su labor y compromiso para atender a la comunidad en la cuestión de alimentación nutritiva, como son:

- Premio a la Excelencia otorgado por el Instituto Argentino de la Excelencia (IADE) en agosto de 2007.

- Distinción de la Asociación Celíaca Argentina - sede Reconquista- por la labor de la UNL en la Investigación y Presentación de Productos sin TACC.

- Distinción del Centro de Implementación de Políticas Públicas para la Equidad y el Crecimiento por considerarlo una actividad que fomenta la educación alimentaria, en mayo de 2012.

Por otra parte hay que destacar que los Alimentos Nutritivos de la UNL fueron presentados en el Foro Internacional para el Desarrollo y la Ayuda Humanitaria (AIDF) en mayo de 2013 en la ciudad de Washington DC, Estados Unidos.

\section{En números}

5 son los productos de alto valor nutricional que elabora la Planta.

5 son los comedores universitarios de universidades nacionales que incorporaron alimentos nutritivos.

300 personas físicas, empresas y otras instituciones se constituyeron en Asociados Solidarios desde que se inició la Planta.

8 toneladas de alimentos mensuales son las que se reparten a partir de ese concepto.

\section{Datos balance 2012}

450000 raciones de alimentos produjeron y se distribuyeron en localidades de Santa Fe y Entre Ríos.

73630 raciones fueron donadas a 32 organizaciones sociales e instituciones de la región a partir de la figura del Asociado Solidario.

\section{Donaciones}

La donación mínima para los ciudadanos que quieran asociarse es equivalente a 10 raciones de alimentos y de 100 raciones para las empresas e instituciones.

\section{Consultas}

Secretaría de Extensión

Programa de Alimentos de Interés Social Junín 3444/46 Planta Alta. 3000 Santa Fe Tel: +54-342 - 4571193

E-mail: alimentosnutritivos@unl.edu.ar Web: www.unl.edu.ar 